\title{
How Environmental Awareness and Knowledge Affect Urban Residents' Willingness to Participate in Rubber Plantation Ecological Restoration Programs: Evidence from Hainan, China
}

\author{
Yu Gan, Tao Xu *DiD, NengRui Xu, JiLv Xu and Dan Qiao \\ Management School, Hainan University, Haikou 570228, China; ganyu84@outlook.com (Y.G.); \\ xunengrui@hainanu.edu.cn (N.X.); xujilv22@outlook.com (J.X.); qiaodan1124@hainanu.edu.cn (D.Q.) \\ * Correspondence: xutao_2013@outlook.com; Tel.: +86-158-7765-5809
}

Citation: Gan, Y.; Xu, T.; Xu, N.; Xu, J.; Qiao, D. How Environmental Awareness and Knowledge Affect Urban Residents' Willingness to Participate in Rubber Plantation Ecological Restoration Programs: Evidence from Hainan, China. Sustainability 2021, 13, 1852.

https://doi.org/10.3390/su13041852

Academic Editor: Roger Jones

Received: 17 January 2021

Accepted: 5 February 2021

Published: 8 February 2021

Publisher's Note: MDPI stays neutral with regard to jurisdictional claims in published maps and institutional affiliations.

Copyright: (c) 2021 by the authors. Licensee MDPI, Basel, Switzerland. This article is an open access article distributed under the terms and conditions of the Creative Commons Attribution (CC BY) license (https:/ / creativecommons.org/licenses/by/ $4.0 /)$.

\begin{abstract}
The rapid expansion of rubber plantations in Asian countries has led to various environmental problems. Therefore, local governments are implementing rubber plantation ecological restoration (RPER) programs as an essential solution. However, such programs can be implemented only if residents are intensely involved. Based on a survey of 521 urban households in Hainan Province, China, this study investigates the effect of environmental awareness and knowledge on residents' willingness to participate in RPER programs. We employ a double-hurdle (DH) model to estimate residents' participation in two stages. First, we determine whether residents wish to participate or not (PN). Then, we measure residents' degree of willingness to participate (DWP). The results show that residents' environmental awareness has a significant positive effect on whether they wish to PN but has no impact on their DWP. By contrast, residents' environmental knowledge has a significant positive effect on whether they wish to PN and their DWP. The moderating effect shows that residents' environmental knowledge significantly weakens the positive effects of their environmental awareness on whether they wish to PN. Moreover, residents' age, educational level, employment, and place of residence substantially influence their DWP. The findings in this study can provide useful insights for policymaking on improving rubber plantation ecosystems.
\end{abstract}

Keywords: environmental awareness; environmental knowledge; ecological restoration; willingness to participate; rubber plantation; double-hurdle model

\section{Introduction}

Since the 1960s, rubber plantations have been rapidly expanding in developing Asian countries, with the total planting area of rubber trees increasing by 196\% from 3.57 million ha in 1961 to 10.57 million ha in 2018 [1]. The development of the natural rubber industry has contributed to economic growth in some regions with low economic development levels. However, the rapid expansion of rubber plantations has damaged local tropical rainforest ecosystems and led to various ecological and environmental problems, such as a weakened climate-moderating capacity, biodiversity loss, and soil erosion [2,3]. Consequently, restoring and protecting the ecosystems threatened by natural rubber plantations have become urgent issues in Asian rubber-planting countries [4,5].

As a natural rubber-producing country, China also faces severe ecological and environmental problems due to rubber plantation expansion. In this context, the Chinese government is implementing rubber plantation ecological restoration (RPER) programs as an essential solution to these issues. RPER programs can effectively improve the ecological functions of plantations, enrich biodiversity, and improve ecological processes by harmonizing the relationship between rubber production activities and the external environment [6,7]. However, because of limited funding and technology, as well as the influence of relevant policies, regulations, and other factors, government-led RPER programs have not been implemented effectively [8]. 
The practical implementation of ecological restoration programs requires the participation of multiple stakeholders [9,10]. In addition to the government, rubber farmers are important actors in improving rubber plantation ecosystems, and the roles of these farmers have received some scholarly attention. For instance, Min et al. analyzed the willingness of rubber farmers in Xishuangbanna Prefecture, Yunnan Province, to participate in activities designed to improve rubber plantation ecosystems and found that they had a relatively positive attitude toward such participation. It was also observed that wealth accumulation and environmental awareness have significant positive effects on willingness to participate [11]. In relevant studies, scholars have found that farmers often refrain from initiating ecosystem improvement activities due to their poor economic conditions, which leads to slow progress in the implementation of ecological restoration programs [12-14]. Externality theories suggest that ecological restoration activities enable rubber farmers to generate obvious external and social-ecological benefits pursued by external beneficiaries (e.g., urban residents) $[15,16]$. Hence, the attitudes and desires of external beneficiaries need to be considered when the government is trying to win public support for ecological restoration policies and measures. However, existing studies on RPER have mostly focused on two types of actors, i.e., the government and farmers, and neglect external beneficiaries.

Ecological restoration programs can effectively improve residents' quality of life and promote the environmental condition of neighboring regions. Therefore, as the beneficiaries of ecological restoration programs, neighboring residents are encouraged to participate in such programs $[17,18]$. Several studies have shown that public participation can effectively facilitate ecological restoration programs, including those related to water environment restoration, waste recycling reuse, public service provision, and ecological tourism resources [19-24]. In addition, factors such as individual characteristics and wealth have been verified to influence the public's willingness to participate $[25,26]$. Significantly, as critical driving factors of residents' pro-environmental behaviors, environmental awareness and knowledge have gradually attracted widespread scholarly attention [27-30]. In this regard, it can be assumed that public participation in RPER programs is also affected by environmental awareness and knowledge. However, the ecological and environmental problems caused by rubber planting are usually not as easy to perceive and comprehend as other regular problems (such as water pollution, desertification, and air pollution). During our field survey, we found that the respondents had different perceptions of the ecological problems stemming from rubber tree planting. Some of them lacked awareness of the ecological and environmental problems stemming from rubber tree planting. For instance, some respondents believed that rubber plantations are "green" and "environmentally friendly," while others even thought that the government should reward rubber-planting farmers for growing carbon sinks in their rubber tree planting activities. Therefore, the influence of the public's awareness and knowledge on its willingness to participate in RPER programs may be different from the conclusion of existing studies. Thus, this study focuses on the impacts of environmental awareness and knowledge on residents' willingness to participate in RPER programs.

Environmental awareness is an individual's understanding and consciousness of ecological and environmental problems [31-34]. Individuals who are aware of environmental issues and the impacts of environmental change are more likely to reduce environmental damage [35]. Previous studies have examined the relationship between individuals' environmental awareness and their willingness to take ecological restoration actions. For instance, Eiswerth et al. (2001) investigated how environmental awareness affects the public's participation in invasive species management programs for lakes [36]. They found that people with a high educational level or frequent contact with lakes are mostly conscious of the damage that invasive species can cause to lake ecosystems and are more likely to support invasive species management programs. Kamaruddin et al. (2016) assessed the environmental awareness level of some communities. They concluded that the public is aware of various environmental problems. However, its participation is low due to lack of time and interest [37]. In general, individuals with a higher degree of environmental 
awareness often have more proactive attitudes toward the environment and are more inclined to engage in pro-environmental behaviors [38]. Although there is no literature on the impact of environmental awareness on residents' participation in RPER programs, we expect that residents who have environmental awareness of the ecological problems caused by natural rubber cultivation will be more inclined to support RPER programs [39].

Meanwhile, environmental knowledge is an individual's perception and understanding of ecosystem structures, functions, and improvement programs [29]. Some empirical studies have shown that environmental knowledge has a positive effect on individuals' willingness to participate in ecosystem improvement and environmental protection activities $[27,40]$. For example, Pothitou (2016) found that residents who are more knowledgeable about the environment are more willing to take environmental protection actions [41]. Gifford et al. (2014) argued that environmental knowledge is an essential but insufficient condition for environmental actions [42]. Ogbeide et al. (2015) showed that consumers with more knowledge of green products are more likely to pay for environmentally friendly products [43]. In general, it is easier for individuals with environmental knowledge to overcome mental barriers such as a lack of awareness, fear, or misunderstanding. In contrast, individuals who lack environmental knowledge have difficulty making wise participation decisions [44-46]. Therefore, we expect that residents with a greater understanding of RPER programs will be more willing to participate in them.

Although most studies indicate that both subjective environmental awareness and objective environmental knowledge can promote a person's participation in ecological restoration programs, there are different understandings of the relationship between environmental awareness and experience and their influence on a person's willingness to participate. Some scholars argue that environmental knowledge is part of environmental awareness and should be treated as its perceptual component [47]. Otto and Pensini (2017) found that environmental knowledge determines only $2 \%$ of a person's environmental behaviors [48]. In addition, Kollmuss and Agyeman (2002) noted that environmental knowledge indirectly influences people's environmental protection behaviors [49]. Steg and Vlek (2009) suggested that environmental knowledge leads to improved awareness of environmental problems [50]. Bassi et al. (2019) discovered that when relevant knowledge is absent, the public's awareness of general environmental problems is more substantial than its awareness of specific environmental problems [30]. Despite their different opinions, most scholars agree that environmental knowledge influences an individual's environmental awareness and behaviors (e.g., it may have some moderating effect on an individual's environmental awareness and actions). Hence, we assume that residents' environmental knowledge affects the relationship between their environmental awareness and their willingness to participate in RPER programs.

The primary objective of this study is to investigate the impacts of environmental awareness and knowledge on residents' willingness to participate in RPER programs. This study is expected to make three contributions to the literature. First, hierarchical regression is applied to test the moderating effect of environmental knowledge on the relationship between residents' environmental awareness and their willingness to participate, thus revealing the mechanism by which environmental knowledge and understanding influence the willingness to participate. Second, to further elucidate these influencing mechanisms, residents' participation decision-making is examined based on two aspects: Whether they wish to participate or not (PN) and the degree of willingness to participate (DWP). Then, a double-hurdle (DH) model is used to examine the influence on each aspect. Meanwhile, we use a combined analysis to assess the moderating effect on these two aspects simultaneously to avoid potential estimation errors. Third, this study fills the existing gap regarding the role of external beneficiaries in rubber plantation ecosystem improvement actions and provides a theoretical and empirical reference for policymaking on RPER.

The structure of this paper is as follows. In Section 2, we describe the econometric analysis model of residents' willingness to participate in ecological restoration. Section 3 introduces the study area and data collection process and gives a statistical profile of the 
sample residents. We then discuss and present the analytical results in Section 4, including the explanatory variables, the control variables, and the influence of the moderating effects. We also analyze the marginal effects and conduct a robustness test on the modeling results. In the final section, we summarize the study and make some policy recommendations.

\section{Econometric Model}

\subsection{DH Model}

A DH model is a two-stage estimation method that is widely applied in studies of individual behavior. It divides the decision-making process into two stages, each of which can have a different determining mechanism [51-53]. In this study, we divided residents willingness to participate into two stages. The first stage is the wish to PN, and the second stage is the DWP. In the first stage, the dependent variable is a dummy variable (that takes the value of only 1 or 0 , indicating participation or not, respectively). In the second stage, the dependent variable is continuous. Hence, if a fair number of residents do not participate in ecological restoration (the value of the dependent variable is 0 ), multiple sample values will be 0 , which in econometrics is known as a corner solution. Since the 0 value represents the rational choice of individuals, the Heckman selection model is inapplicable [54,55]. In this paper, we used the DH model to handle corner solutions.

Specifically, in the first stage, residents decide to participate based on the random utility framework [56,57]. In the formula, $d_{i}^{*}$ represents the difference between the utility of participating $\left(U_{i P}\right)$ and the utility of not participating $\left(U_{i N}\right)$ in an ecosystem improvement project. If $d_{i}^{*}=U_{i P}-U_{i N}>0$, a resident chooses to participate in the ecological restoration project. However, these two utilities are subjective and unobservable. They can be expressed as latent variables, and their values are a function of the observable variables in the model. Hence, the model for stage 1 is as follows:

$$
d_{i}^{*}=\alpha X_{i}+u_{i} ; u_{i} \sim N(0,1) \text { and } d_{i}= \begin{cases}1 & \text { if } d_{i}^{*}>0 \\ 0 & \text { otherwise }\end{cases}
$$

where $i$ represents respondent $i$, and $d_{i}^{*}$ is the latent variable of $d_{i}$. A value of $d_{i}=1$ means that a resident chooses to participate in RPER, while $d_{i}=0$ means nonparticipation.

The model for the second stage takes the following form:

$$
y_{i}=\beta Z_{i}+v_{i} ; v_{i} \sim N\left(0, \sigma^{2}\right) \text { and } y_{i}=\left\{\begin{array}{cc}
y_{i}^{*} & \text { if } y_{i}^{*}>0 \text { and } d_{i}=1 \\
0 & \text { otherwise }
\end{array}\right.
$$

where $y_{i}$ is resident's DWP in RPER; $y_{i}^{*}$ is the latent variable of $y_{i}$, and $X_{i}$ and $Z_{i}$ are vectors containing the explanatory variables, including the main explanatory variables (environmental awareness, environmental knowledge, and their interactive item) and the control variables (the individual characteristic variables, the area dummy variables, etc.). The explanatory variables of the two stages can be different. $\alpha$ and $\beta$ are correlation coefficients, and $\mu_{i}$ and $v_{i}$ are random errors.

Based on Equations (1) and (2), we created the following log-likelihood function based on the DH model:

$$
\begin{gathered}
L\left(y_{i} \mid x_{i}, \theta\right)=\prod_{y_{i}=0}\left[1-\Phi\left(x_{i} \alpha / \sigma_{u}\right)\right] \Phi\left(z_{i} \beta / \sigma_{v}\right)^{*} \prod_{y_{i}>0} \Phi\left(x_{i} \alpha / \sigma_{u}\right) \Phi\left(z_{i} \beta / \sigma_{v}\right) \\
\times \frac{\phi\left[\left(y_{i}-z_{i} \beta\right) / \sigma_{v}\right]}{\sigma_{v} \Phi\left(z_{i} \beta / \sigma_{v}\right)}
\end{gathered}
$$

where $\varphi$ and $\Phi$ are the probability density function and the cumulative distribution function of a normal distribution, respectively; $\sigma_{u}$ is the standard deviation of $u_{i}$; and $\sigma_{v}$ is the standard deviation of $v_{i}$. The form of $\left[1 / \Phi\left(z_{i} \beta / \sigma_{v}\right)\right]$ guarantees that the density is integrated as $y_{i}>0$. Function (5) allows us to compute the values of $\alpha, \beta$, and $\sigma^{2}$ based on the maximum likelihood estimates. 


\subsection{Assessing the Moderating Effect}

We applied a moderating effect model to assess the influences of environmental knowledge on the relationship between residents' environmental awareness and willingness to participate. When the moderating effect is considered, it is often necessary to normalize the independent variables and the moderators [58]. In this paper, the model of the moderating effect on residents' willingness to participate was as follows:

$$
P_{i}=\chi E A_{i}+\gamma E K_{i}+\eta E A_{i} \cdot E K_{i}+\lambda X_{i}+\sigma
$$

where $P_{i}$ is the willingness to participate (including the wish to PN and the DWP) of resident $i$; $E A_{i}$ and $E K_{i}$ represent the environmental awareness and environmental knowledge of resident $I$, respectively, $X_{i}$ is the control variables, e.g., the individual characteristic variables and area dummies; and $\chi, \gamma, \eta$, and $\lambda$ are regression coefficients; and $\sigma$ is the error. Equation (4) can be changed into the following form:

$$
P_{i}=\gamma E K_{i}+\left(\chi+\eta E K_{i}\right) E A_{i}+\lambda X_{i}+\sigma
$$

where the regression coefficient $\left(\chi+\eta E K_{i}\right)$ measures the relationship between the willingness to participate and the environmental awareness of resident $i$, which is a function of $E K_{i}$; and $\eta$ measures the moderating effect of resident $i$ 's environmental knowledge on the relationship between that resident's environmental awareness and willingness to participate.

\subsection{Marginal Effect Analysis}

The correlation coefficients of the variables in the DH model can explain only part of the relationship between environmental awareness and knowledge and residents' willingness to participate. In this paper, we also used Burke's (2009) method and calculated the marginal effects of the explanatory variables on residents' willingness to participate in the two stages to better understand the influences of environmental awareness and knowledge on residents' willingness to participate [54]. First, we estimated the PN probability of each individual resident $i$ :

$$
P\left(d_{i}^{*}>0 \mid x_{i}\right)=\Phi\left(x_{i} \alpha\right)
$$

Then, we estimated the resident's conditional DWP (i.e., willingness to participate in ecological restoration):

$$
E\left(y_{i}\left|y_{i}\right\rangle 0, z_{i}\right)=z_{i} \beta+\sigma \times \lambda\left(z_{i} \beta / \sigma\right)
$$

In Equation (7), $\lambda\left(z_{i} \beta / \sigma\right)$ is the inverse Mill ratio:

$$
\lambda\left(z_{i} \beta / \sigma\right)=\varphi\left(z_{i} \beta / \sigma\right) / \Phi\left(z_{i} \beta / \sigma\right)
$$

Based on Equations (6) and (7), we estimated the marginal effect of the independent variables in the first stage and the conditional average partial effect (CAPE) of the independent variables in the second stage of the $\mathrm{DH}$ model.

\section{Data}

\subsection{Data Collection}

The data used in the study came from a household survey conducted in Hainan Province, China, in July 2019. Hainan is located in the southernmost part of China and is its most crucial rubber tree production base. In 2018, the rubber tree planting area in Hainan was 528,000 ha, accounting for $45.7 \%$ of China's total rubber tree planting area [1,59]. Since the 1950s, large-scale rubber tree planting has replaced the virgin tropical rainforest on Hainan Island and has caused severe environmental problems [60-62]. We collected data via stratified random sampling. First, we randomly selected four cities: Haikou (northern Hainan Island), Sanya (southern), Danzhou (central), and Wanning (southern) (for details, see the study area in Figure 1). 


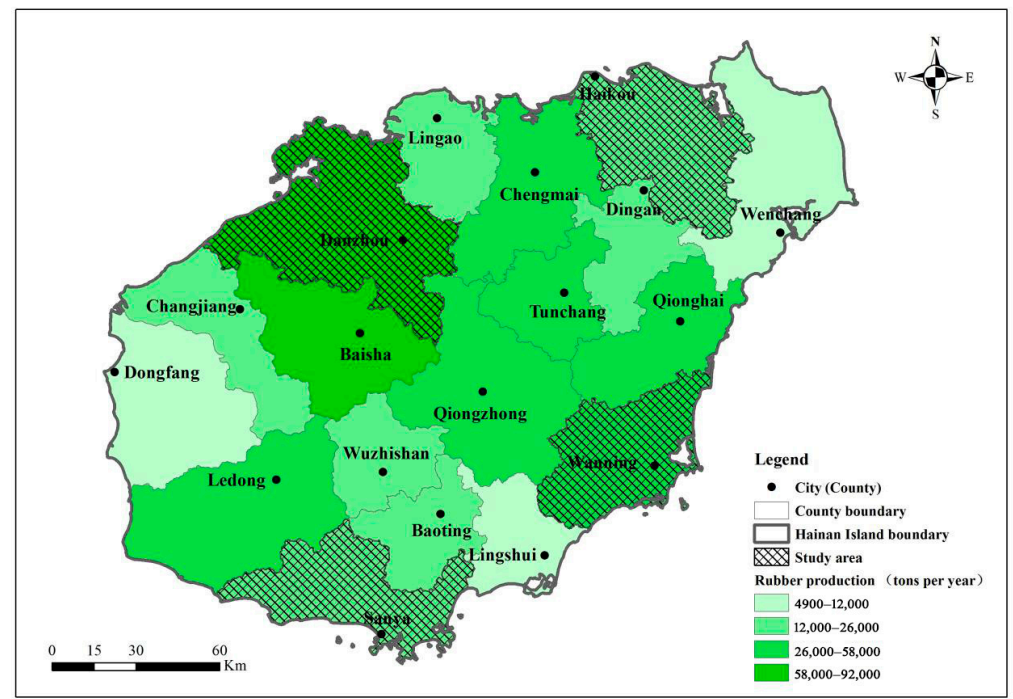

Figure 1. Study area.

These four cities have different economic development levels (gross domestic product (GDP)) and geographic features (status of rubber tree planting). The details are shown in Figure 2. Then, we selected residents of different districts of each city through random sampling. Specifically, the samples included 181 households in the Xiuying, Qiongshan, Meilan, and Longhua Districts of Haikou; 115 households in the Jiyang, Haitang, and Tianya Districts of Sanya; 104 households in Danzhou; and 121 households in Wanning (Danzhou and Wanning are cities at the county level and do not have districts). Thus, we randomly selected households based on the subdistricts of 2 cities and surveyed 521 households. For the survey, we used a structured questionnaire prepared in Chinese. The data collected by the questionnaire included residents' socioeconomic characteristics, their knowledge and awareness of environmental change, their understanding of RPER programs, and their willingness to participate. Before the survey, we provided professional training to all of the investigators to guarantee that the interview approaches and coverage were consistent and to minimize the errors caused by the subjective opinions of the investigators. We then conducted a preliminary test on the questionnaire through an online survey in June 2019 and modified the questionnaire based on the test. Finally, we performed face-to-face interviews with the sampled residents in the study area in July 2019.

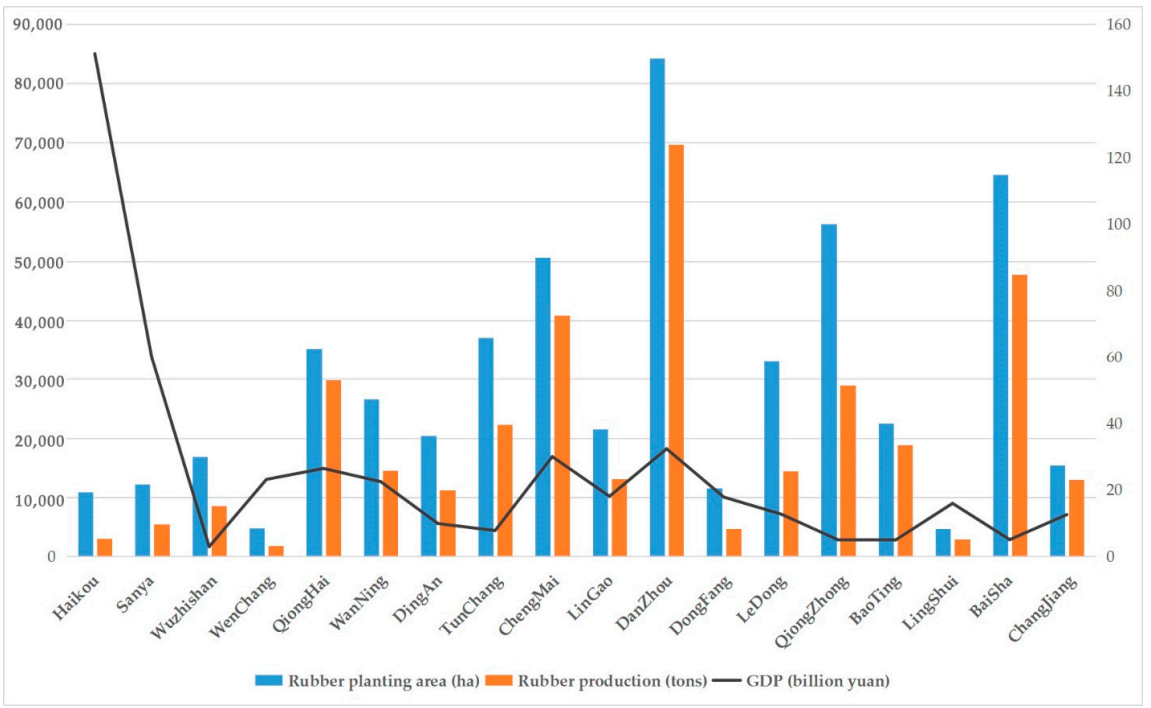

Figure 2. The rubber output, planting area, and gross domestic product (GDP) of all regions in Hainan Province. 


\section{2. $P N$ and $D W P$}

We measured residents' willingness to participate in RPER programs at two stages. First, we determined whether residents wish to PN. Then, we measured their DWP. PN is a binary variable, and we measured it by asking the interviewed residents whether they were willing to participate in RPER programs. DWP is a continuous variable, measured as residents' willingness to pay (WTP) for RPER programs. To assess residents' WTP, we applied the conditional valuation method (CVM), a survey approach designed to value nonmarket values, revealing the public's WTP for specified changes in the quantity or quality of nonmarket goods [63]. Through the design of the questionnaire in this study, we described the particular scenario (rubber expansion has caused some ecological and environmental problems) to the survey respondents and made the presented RPER programs public goods. We then let the respondents give their payments in elicitation formats.

In the CVM survey, elicitation formats are critical: They directly determine the accuracy of WTP evaluation. Elicitation formats such as open-ended (OE) and payment cards (PCs) are widely applied in CVM studies because they are simple and straightforward $[64,65]$. However, in practice, these two approaches also pose some obstacles. For instance, respondents may find it challenging to answer OE questionnaires. Although the PC approach can dramatically reduce such difficulties, it tends to generate some starting point deviations [66]. Therefore, in this paper, we followed the example of Whittington et al. (2002) and used both the OE and PC approaches to design the CVM questionnaire to collect data on the respondents' WTP [67].

In our CVM questionnaire, we provided respondents with the following virtual market scenarios: "In RPER programs, rubber plantations will differ from traditional plantations by treating rubber trees as part of a complex ecosystem with multiple species, multiple layers of plants, and a sound biological environment. This change can help improve biodiversity and the ecological functions of rubber plantations. Promoting RPER programs will help improve the local ecological environment, but such activities are expensive and may require your family to pay some fees (equivalent to buying ecological environmental products). Please consider your family's actual circumstances and decide whether you are willing to participate." The options for the question were " $1=$ yes, $0=$ no." If the interviewed residents answered "yes," we proceeded to stage 2 of the WTP survey. The problem in stage 2 read as follows: "All the fees you pay will be used for RPER programs. Please indicate the maximum amount you are willing to pay." For the elicitation formats, we first asked the respondents an $\mathrm{OE}$ question. When it was difficult for the respondents to specify a WTP amount, we provided them with multiple PCs as different options. We designed the PC options based on the studies by Solomon (2009) and Sardana et al. (2019) $[68,69]$. Based on the preliminary online survey results, we roughly estimated the scope of respondents WTP for RPER programs and determined the specific amounts to put on the PCs (" $0,5,10$ ... 900, 1000, more than $\left.1000 \mathrm{RMB}^{\prime \prime}\right)$.

\subsection{Statistical Profile of the Variables}

As shown in Table 1, 429 of the 521 respondents, i.e., $82.34 \%$, were willing to participate in RPER programs, indicating residents' high willingness to participate. Furthermore, among the 429 respondents, $27.84 \%$ of the residents had a WTP for RPER programs of less than RMB 50, 28.6\% had a WTP between RMB 50 and 100, 29.74\% were willing to pay between RMB 100 and 200, and $16.32 \%$ were willing to pay more than RMB 200.

This paper's core independent variables are environmental awareness and environmental knowledge. Environmental awareness refers to whether residents are aware of the environmental problems caused by natural rubber plantations. To measure their environmental awareness, we asked residents the following question: "Do you agree that rubber plantation hurt Hainan's ecosystem?" The respondents were asked to choose from the following options: " 5 = strongly agree," " $4=$ agree," " $3=$ uncertain or unsure," " $2=$ disagree," and " 1 = strongly disagree." In total, the residents' average environmental awareness was 2.775 , with a standard deviation of 1.227 , showing that the environmental awareness of 
residents of Hainan Province was at a medium level. Environmental knowledge reflects residents' understanding of knowledge about the ecological environment, such as RPER programs' mechanisms for preventing biodiversity reduction, controlling soil erosion, and so on. To measure residents' environmental knowledge, we asked them the following question: "Do you know about some RPER programs that have been implemented and how they work?" The response options included the following: " $5=$ very much," " $4=$ much," " 3 = average," " $2=$ a little," and " $1=$ hardly any." The statistical results indicate that the average environmental knowledge was 1.681, with a standard deviation of 0.862 , which means that the residents of Hainan Province generally had a low level of knowledge about RPER.

Table 1. Willingness to pay (WTP) distribution.

\begin{tabular}{cccc}
\hline WTP/Yuan & Frequency & Percent/\% & Cum. \\
\hline WTP $=0$ & 92 & 17.66 & 17.66 \\
$0<\mathrm{WTP} \leq 50$ & 145 & 27.84 & 45.49 \\
$50<\mathrm{WTP} \leq 100$ & 149 & 28.6 & 74.09 \\
$100<\mathrm{WTP} \leq 200$ & 155 & 29.74 & 83.69 \\
$200<\mathrm{WTP} \leq 500$ & 36 & 6.91 & 90.60 \\
WTP $>500$ & 49 & 9.41 & 100.00 \\
Total & 521 & 100 & $/$ \\
\hline
\end{tabular}

In addition, considering that residents' characteristics may affect their willingness to participate in ecological restoration programs, we took their gender, age, educational level, employment, and family burden as control variables. Moreover, to control for the influences of regional differences, we included the study region as a control variable in the model. We used the number of years of school education to measure residents' educational level. Additionally, we used whether the head of household had a job to access the respondents' employment. Furthermore, we used the dependency ratio (the number of members not of labor-force age versus the number of labor-force members in a household) to determine family burden. The statistical results indicate that the majority (56\%) of the respondents were male, the average age was 32.8 years, the average educational level was 12.66 years, the employment rate was $93.5 \%$, and the average family burden (dependency ratio) was 0.98 . The descriptive statistics of the total variables were shown in Table 2.

Table 2. Descriptive statistics of the variables.

\begin{tabular}{|c|c|c|c|}
\hline Variables & Definitions & Mean & Std. Dev \\
\hline \multicolumn{4}{|l|}{ Dependent } \\
\hline PN & The respondents' willingness to participate ( $1=$ yes; $0=$ otherwise $)$ & 0.823 & 0.382 \\
\hline DWP & The degree of willingness to participate, measured by the respondents' WTP (yuan) & 174.129 & 291.326 \\
\hline \multicolumn{4}{|c|}{ - } \\
\hline En-awareness & The environmental awareness of the interviewed residents (1-5) & 2.775 & 1.227 \\
\hline En-knowledge & The respondents' knowledge of RPER programs (1-5) & 1.681 & 0.863 \\
\hline $\mathrm{EA} \times \mathrm{EK}$ & The interaction of environmental awareness and environmental knowledge & 0.138 & 1.089 \\
\hline \multicolumn{4}{|c|}{ ( } \\
\hline Gender & The gender of the respondents $(1=$ male; $0=$ female $)$ & 0.56 & 0.497 \\
\hline Age & The age of the respondents (years) & 32.804 & 10.558 \\
\hline Education & The educational level of the respondents (years) & 12.658 & 3.416 \\
\hline Work & Whether the respondents are employed $(1=$ yes; $0=$ otherwise $)$ & 0.935 & 0.247 \\
\hline Burden & The ratio of those of labor-force age to those not of labor-force age in the population & 0.984 & 0.894 \\
\hline Sanya & Regional dummy variables & 0.221 & 0.415 \\
\hline Danzhou & ( $1=$ live in this area; & 0.2 & 0.4 \\
\hline Haikou & $0=$ otherwise) & 0.347 & 0.477 \\
\hline
\end{tabular}




\section{Estimation Results \\ 4.1. Model Estimation Results}

In this paper, we used a DH model to analyze the factors influencing residents' willingness to participate in RPER and conducts a stratified regression from Models 1 to 3 . Model 1 examines the main effect of environmental awareness' on residents' willingness to participate (including their wish to PN and their DWP). Model 2 adds environmental knowledge to Model 1 for the main effect analysis. Model 3 adds the interactions between environmental awareness and knowledge to Model 2 to examine the moderating effects of environmental knowledge on the relationship between residents' environmental awareness and willingness to participate in RPER. As the independent and moderating variables were continuous, we used a stratified regression to analyze and test the moderating effects and normalized both the independent and moderating variables [58]. Table 3 shows the modeling results. The Wald chi-square tests in Models 1 and 3 were statistically significant at the $1 \%$ level, indicating an overall good degree of fit.

Table 3. Estimation results of the double-hurdle (DH) model.

\begin{tabular}{|c|c|c|c|c|c|c|}
\hline \multirow[b]{2}{*}{ Variables } & \multicolumn{2}{|c|}{ Model 1} & \multicolumn{2}{|c|}{ Model 2} & \multicolumn{2}{|c|}{ Model 3} \\
\hline & $\begin{array}{c}\text { Hurdle I } \\
\text { PN }\end{array}$ & $\begin{array}{c}\text { Hurdle II } \\
\text { DWP }\end{array}$ & $\begin{array}{c}\text { Hurdle I } \\
\text { PN }\end{array}$ & $\begin{array}{c}\text { Hurdle II } \\
\text { DWP }\end{array}$ & $\begin{array}{c}\text { Hurdle I } \\
\text { PN }\end{array}$ & $\begin{array}{c}\text { Hurdle II } \\
\text { DWP }\end{array}$ \\
\hline En-awareness & $\begin{array}{c}0.199^{1 * * *} \\
(0.056)^{2}\end{array}$ & $\begin{array}{c}16.727 \\
(12.216)\end{array}$ & $\begin{array}{c}0.176^{* * *} \\
(0.057)\end{array}$ & $\begin{array}{c}14.351 \\
(12.036)\end{array}$ & $\begin{array}{c}0.389 * * * \\
(0.126)\end{array}$ & $\begin{array}{c}6.291 \\
(21.986)\end{array}$ \\
\hline En-knowledge & & & $\begin{array}{c}0.273^{* * *} \\
(0.091)\end{array}$ & $\begin{array}{c}75.845^{* * *} \\
(19.955)\end{array}$ & $\begin{array}{c}0.682 * * * \\
(0.244)\end{array}$ & $\begin{array}{c}62.296 \\
(43.836)\end{array}$ \\
\hline $\mathrm{EA} \times \mathrm{EK}$ & & & & & $\begin{array}{c}-0.143 \text { * } \\
(0.075)\end{array}$ & $\begin{array}{c}4.616 \\
(12.817)\end{array}$ \\
\hline Gender & $\begin{array}{c}0.147 \\
(0.142)\end{array}$ & $\begin{array}{c}26.135 \\
(29.923)\end{array}$ & $\begin{array}{c}0.119 \\
(0.143)\end{array}$ & $\begin{array}{c}6.515 \\
(30.099)\end{array}$ & $\begin{array}{c}0.137 \\
(0.145)\end{array}$ & $\begin{array}{c}6.294 \\
(30.154)\end{array}$ \\
\hline Age & $\begin{array}{c}-0.017 * * * \\
(0.006)\end{array}$ & $\begin{array}{l}-3.121^{* *} \\
(1.228)\end{array}$ & $\begin{array}{c}-0.017^{* * *} \\
(0.006)\end{array}$ & $\begin{array}{l}-2.457^{* *} \\
(1.192)\end{array}$ & $\begin{array}{l}-0.015^{* *} \\
(0.006)\end{array}$ & $\begin{array}{l}-2.476^{* *} \\
(1.192)\end{array}$ \\
\hline Education & $\begin{array}{c}0.058^{* * *} \\
(0.021)\end{array}$ & $\begin{array}{c}10.136 \text { * } \\
(5.457)\end{array}$ & $\begin{array}{c}0.051 * * \\
(0.021)\end{array}$ & $\begin{array}{c}8.285 \\
(5.263)\end{array}$ & $\begin{array}{c}0.048^{* * *} \\
(0.021)\end{array}$ & $\begin{array}{c}8.344 \\
(5.274)\end{array}$ \\
\hline Work & $\begin{array}{c}0.265 \\
(0.319)\end{array}$ & $\begin{array}{l}101.035 \text { * } \\
(57.132)\end{array}$ & $\begin{array}{c}0.182 \\
(0.321)\end{array}$ & $\begin{array}{c}84.855 \\
(56.090)\end{array}$ & $\begin{array}{c}0.182 \\
(0.323)\end{array}$ & $\begin{array}{c}85.157 \\
(55.992)\end{array}$ \\
\hline Burden & $\begin{array}{c}0.055 \\
(0.080)\end{array}$ & $\begin{array}{c}18.482 \\
(16.073)\end{array}$ & $\begin{array}{c}0.052 \\
(0.082)\end{array}$ & $\begin{array}{c}16.621 \\
(16.371)\end{array}$ & $\begin{array}{c}0.046 \\
(0.082)\end{array}$ & $\begin{array}{c}16.865 \\
(16.380)\end{array}$ \\
\hline Sanya & $\begin{array}{l}-0.002 \\
(0.187)\end{array}$ & $\begin{array}{l}-34.656 \\
(44.086)\end{array}$ & $\begin{array}{c}0.045 \\
(0.191)\end{array}$ & $\begin{array}{l}-21.071 \\
(43.683)\end{array}$ & $\begin{array}{c}0.041 \\
(0.191)\end{array}$ & $\begin{array}{l}-21.063 \\
(43.793)\end{array}$ \\
\hline Danzhou & $\begin{array}{c}0.558^{* * *} \\
(0.215)\end{array}$ & $\begin{array}{c}20.403 \\
(45.104)\end{array}$ & $\begin{array}{c}0.599 * * * \\
(0.218)\end{array}$ & $\begin{array}{c}45.304 \\
(44.976)\end{array}$ & $\begin{array}{c}0.589 * * * \\
(0.218)\end{array}$ & $\begin{array}{c}45.485 \\
(45.048)\end{array}$ \\
\hline Haikou & $\begin{array}{l}0.340 * \\
(0.180)\end{array}$ & $\begin{array}{l}-9.397 \\
(44.327)\end{array}$ & $\begin{array}{l}0.390^{* *} \\
(0.182)\end{array}$ & $\begin{array}{c}18.788 \\
(44.345)\end{array}$ & $\begin{array}{l}0.380^{* *} \\
(0.183)\end{array}$ & $\begin{array}{c}18.780 \\
(44.402)\end{array}$ \\
\hline Constant & $\begin{array}{l}-0.076 \\
(0.424)\end{array}$ & $\begin{array}{c}98.539 \\
(102.109)\end{array}$ & $\begin{array}{l}-0.388 \\
(0.440)\end{array}$ & $\begin{array}{l}-29.045 \\
(96.710)\end{array}$ & $\begin{array}{c}-0.984 * \\
(0.549)\end{array}$ & $\begin{array}{c}-6.041 \\
(108.473)\end{array}$ \\
\hline Observations & 521 & 429 & 521 & 429 & 521 & 429 \\
\hline $\begin{array}{l}\text { Log-likelihood } \\
\text { LR chi }{ }^{2}(9)\end{array}$ & $\begin{array}{c}-218.86754 \\
48.02^{* * *}\end{array}$ & & $\begin{array}{c}-214.0078 \\
57.74^{* * *}\end{array}$ & & $\begin{array}{c}-212.21946 \\
61.31^{* * *}\end{array}$ & \\
\hline
\end{tabular}

\subsection{The Influences of Environmental Awareness and Knowledge on Residents' Willingness to Participate}

Table 3 presents the estimated results of the effect of environmental awareness on residents' willingness to participate in RPER programs. In Hurdle I, environmental awareness had a significant (at the 1\% level) impact on residents' wish to PN, but in Hurdle II, the impact of environmental awareness on residents' DWP was not significant. These results indicate that residents with strong environmental awareness are more willing to participate in RPER programs. However, environmental awareness does not directly affect their DWP. 
Model 2, which includes environmental knowledge, shows that environmental knowledge positively affected residents' wish to PN and DWP in both hurdles, and this effect was statistically significant at the $1 \%$ level. The results indicate that when residents are more knowledgeable about RPER, they have a higher willingness to participate. Moreover, residents' knowledge about ecological restoration programs directly affects their participation degree. In summary, environmental awareness affected only residents' wish to PN, while environmental knowledge affected both residents' wish to PN and their DWP.

\subsection{The Moderating Effects of Environmental Knowledge}

Model 3 introduces the interaction between environmental awareness and environmental knowledge to examine whether environmental knowledge enhances or weakens the positive impact of environmental awareness on residents' willingness to participate. First, in Hurdle I, the results show that environmental knowledge negatively moderated the effect of environmental awareness on residents' wish to PN, and this effect was statistically significant at the $10 \%$ level, indicating that environmental knowledge affects the relationship between residents' environmental awareness and their wish to PN and that the moderating effect is negative. Second, in Hurdle II, the results show that environmental knowledge positively moderated the effect of environmental awareness on residents' DWP. The moderating effect was nonsignificant, indicating that environmental knowledge has little moderating impact on the relationship between residents' environmental awareness and their DWP.

To more clearly and intuitively illustrate the moderating effect in Hurdle I, we drew a diagram, as shown in Figure 3. When residents' environmental knowledge level is low, it is more likely that environmental knowledge will have a more substantial moderating effect on the correlation between residents' environmental awareness and their wish to PN (with a higher slope). In contrast, when their environmental knowledge level is high, its moderating effect will be smaller (with a smaller slope). The causes of such results are worth discussion. Specifically, environmental awareness and environmental knowledge can directly affect residents' willingness to participate in ecological restoration actions. However, participation decisions based on environmental awareness tend to be more subjective, while those based on environmental knowledge tend to be more objective. Residents with high environmental knowledge levels (i.e., those who know more about the ecological restoration programs) are more inclined to base their decisions on their environmental knowledge than to base their decisions on their subjective environmental awareness $[48,53]$.

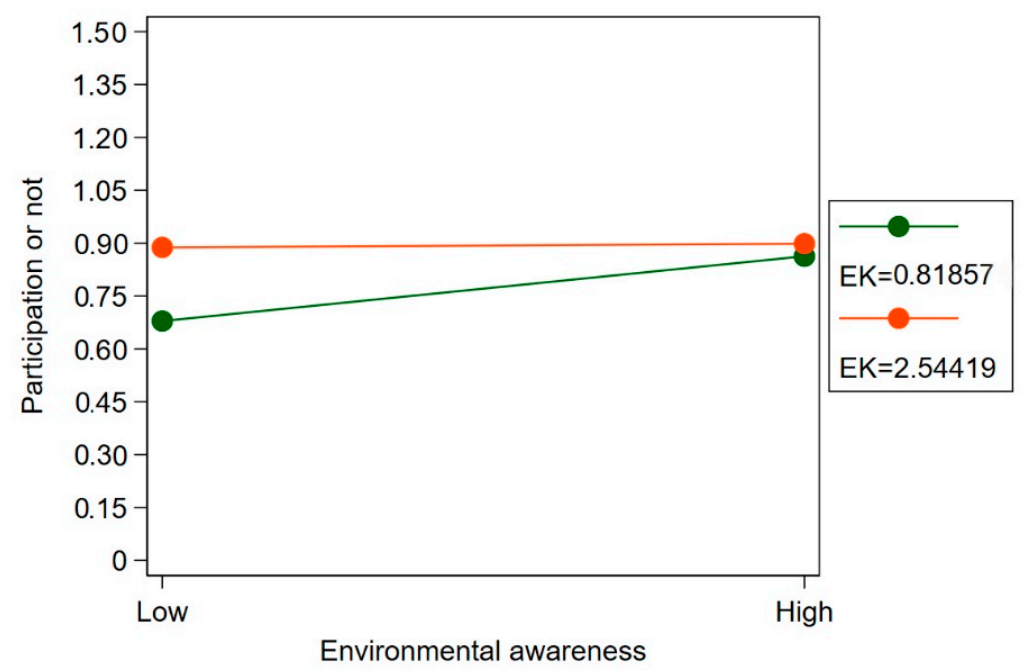

Figure 3. Moderating effect of environmental knowledge. EK represents residents' degree of environmental knowledge. 
In contrast, residents with less environmental knowledge may rely only on their subjective environmental awareness to make decisions. Hence, environmental knowledge has adverse moderating effects on the relationship between environmental awareness and willingness to participate. Some previous studies on the moderating effects of environmental knowledge on individuals' behavior have reached similar conclusions. For instance, Haryanto's (2014) empirical research on Indonesian consumers found that environmental knowledge weakens the positive effects of a "green" brand on consumers' purchasing attitudes [70].

\subsection{The Influences of the Control Variables}

Among the control variables of the residents' characteristics, their age, educational level, and employment had significant positive effects on their willingness to participate in RPER programs. In Models 1 and 2, the respondents' age positively and significantly (at the 1\% level) affected their wish to PN and negatively and significantly (at the 5\% level) affected their DWP. In Model 3, the respondents' age negatively and significantly (at the 5\% level) affected their wish to PN and their DWP. These results mean that older residents tend to have a lower willingness to participate, probably because older residents have less access to relevant information and less exposure to environmental awarenessraising materials and campaigns. Therefore, they have less environmental knowledge and weaker environmental awareness, which affects their participation. The respondents' educational level had a significant positive effect on their wish to PN (in Model 1, the effect was statistically significant at the 1\% level, and in Models 2 and 3, the effect was statistically significant at the 5\% level). In Model 1, educational level positively and statistically (at the 10\% level) affected residents' DWP. In Models 2 and 3, educational level also positively affected residents' DWP. However, the effects were not significant. The results indicate that residents with better education have a higher DWP in ecological restoration actions. A reasonable explanation is that well-educated respondents know more about the importance of ecological-environmental protection. Thus, they are more willing to participate in ecological restoration actions. In Model 1, whether the respondents were employed positively and significantly (at the 10\% level) affected their DWP, indicating that people with a job and a stable income have a high DWP in ecological restoration actions. Finally, in Models 1 and 3, the respondents' gender and family burden (dependency ratios) had no significant PN or DWP effects.

An analysis of the region control variable indicates that residents' willingness to participate in different areas had high heterogeneity. Specifically, in Models 1-3, living in Danzhou had a positive effect on the respondents' wish to PN, and this effect was statistically significant at the 1\% level. In all three models, living in Haikou also positively affected residents' PN (in Model 1, the effect was statistically significant at the 10\% level, while in Models 2 and 3, the effect was statistically significant at the $5 \%$ level). These results indicate that, across different regions of Hainan Province where the natural conditions, economic development level and local culture and customs show heterogeneity, residents' willingness to participate in ecological restoration actions significantly varies. There are two possible reasons for this result. First, as shown in Figure 2, Danzhou is the area with the highest rubber tree production in both planting and output volume. Hence, rubber is an important local industry that is closely related to residents' everyday lives. Therefore, the residents of Danzhou experience more environmental problems due to rubber planting and know more about rubber planting. Thus, they are more inclined to participate in RPER programs. Second, although rubber planting is not an essential industry in Haikou, it is the capital city of Hainan Province, and its educational level, urbanization rate, and economic development level are the highest among cities in Hainan Province. In 2019, Haikou city contributed over $30 \%$ of the provincial GDP [63]. Haikou residents have increased exposure to frequent awareness-raising materials and information on ecosystem protection due to their location. They have more vital environmental awareness than any other residents 
in our study. Moreover, they have higher income levels than the residents of other cities. Hence, they are more willing to participate in RPER programs.

\subsection{Marginal Effect Analysis}

This paper assessed the marginal effects of the models (see Table 4) to reveal how strongly changes in the independent variables influence changes in the dependent variables compared to the regression coefficients. Our marginal effect analysis results show that a $1 \%$ increase in residents' environmental awareness can lead to a $4 \%$ increase in their wish to $\mathrm{PN}$, and this result was statistically significant at the $1 \%$ level. This result also indicates that a 1\% increase in residents' environmental knowledge can cause an increase of $7.3 \%$ in their wish to PN. The CAPE results suggest that among the residents who decide to participate in ecological restoration actions, a $1 \%$ increase in their environmental knowledge can increase their DWP by RMB 75.58, and this result was statistically significant at the $1 \%$ level. Increases in residents' environmental awareness and knowledge can improve their willingness to participate and their degree of participation in ecological restoration actions.

Table 4. Marginal effects for the DH model.

\begin{tabular}{|c|c|c|c|c|}
\hline \multirow{2}{*}{ Variables } & \multicolumn{2}{|c|}{ Hurdle I: PN } & \multicolumn{2}{|c|}{ Hurdle II: DWP } \\
\hline & Marginal effects & Std. Err. & CAPE & Std. Err. \\
\hline En-awareness & $0.040^{1 * * *}$ & 0.013 & 14.371 & 12.204 \\
\hline En-knowledge & $0.073^{* * *}$ & 0.022 & $75.584^{* * *}$ & 17.077 \\
\hline Gender & 0.031 & 0.033 & 6.294 & 30.165 \\
\hline Age & $-0.003^{* *}$ & 0.001 & -2.476 & 1.5118 \\
\hline Education & $0.011 * *$ & 0.005 & $8.344 *$ & 4.5451 \\
\hline Work & 0.041 & 0.073 & 85.157 & 57.279 \\
\hline Burden & 0.010 & 0.019 & 16.865 & 16.580 \\
\hline Sanya & 0.009 & 0.043 & -21.063 & 45.174 \\
\hline Danzhou & $0.133^{* * *}$ & 0.049 & 45.485 & 44.778 \\
\hline Haikou & $0.086^{* *}$ & 0.041 & 18.780 & 40.659 \\
\hline Observations & \multicolumn{2}{|l|}{521} & \multicolumn{2}{|c|}{429} \\
\hline
\end{tabular}

1 *** $p<0.01,{ }^{* * *} p<0.01,{ }^{* *} p<0.05,{ }^{*} p<0.1$.

The control variable results show that a $1 \%$ increase in the respondents' age led to a $0.3 \%$ decrease in their wish to PN, and that a $1 \%$ increase in their educational level caused a $1.1 \%$ increase in their wish to PN. Living in Danzhou and Haikou increased the respondents' wish to PN by $13.3 \%$ and $8.6 \%$, respectively. The CAPE results show that a $1 \%$ increase in the educational level of residents willing to participate led to a DWP increase of $8.34 \mathrm{RMB}$, and this result was statistically significant at the $1 \%$ level. Our marginal effect analysis results further confirm the effects of age and educational level on residents' willingness to participate in ecological restoration actions. Residents' PN had significant regional heterogeneity.

\subsection{Robustness Test}

To test the reliability of the empirical analysis, we conducted a robustness test using a regression on reduced sample size [71]. We randomly deleted $25 \%$ of the sample data (130 observations were randomly chosen and then dropped). After that, we re-estimated the remaining samples. Table 5 presents the DH model assessment results of environmental knowledge, environmental awareness, and the interaction between them after the randomly chosen $25 \%$ of sample data were excluded. Although the coefficient values somewhat changed, the directions of the main explanatory variables and the interaction coefficients remain unchanged. The effect remains significant (Table 5), indicating that the study's conclusions are robust. 
Table 5. Robustness checks of the estimation.

\begin{tabular}{|c|c|c|c|c|}
\hline \multicolumn{2}{|c|}{ Variables } & \multirow{2}{*}{$\begin{array}{c}\begin{array}{c}\text { En-Awareness } \\
\text { (Coef. }^{2} \text { ) }\end{array} \\
0.176^{1 * * *}\end{array}$} & \multirow{2}{*}{$\begin{array}{c}\begin{array}{c}\text { En-Knowledge } \\
\text { (Coef.) }\end{array} \\
0.273^{* * *}\end{array}$} & \multirow{2}{*}{$\begin{array}{c}\begin{array}{c}\text { EA } \times \\
\text { (Coef.) }\end{array} \\
-0.143^{*}\end{array}$} \\
\hline Orioinol mod & Hurdle I & & & \\
\hline Uriginal model & Hurdle II & 14.351 & $75.845^{* * *}$ & 4.616 \\
\hline \multirow{2}{*}{ Deleted sample 3} & Hurdle I & $0.459 * * *$ & $0.936^{* * *}$ & $-0.188^{* *}$ \\
\hline & Hurdle II & 18.638 & $96.020 *$ & 1.718 \\
\hline
\end{tabular}

$1 * * * p<0.01,{ }^{* * *} p<0.01,{ }^{* *} p<0.05,{ }^{*} p<0.1{ }^{2}$ Coef. = coefficient; ${ }^{3}$ We use the "randomtag" command in the Stata software to randomly delete $25 \%$ of the sample data and re-estimate the remaining samples. After repeating the above processes, the estimation results remained stable. This table shows one of the estimation results.

\section{Conclusions}

It is essential to gain public support and participation in RPER programs to protect and restore the ecosystem functions of rubber tree-planting regions. In this study, we divided willingness to participate into two stages. First, we determined whether residents wish to PN. Then, we measured their DWP. We surveyed 521 urban households in Hainan Province, China. We used a DH model to assess the effects of environmental awareness and knowledge on residents' willingness to participate in ecological restoration actions. We also examined the moderating effects of environmental knowledge on the relationship between residents' environmental awareness and their willingness to participate, further assessed the marginal effects of the model, and tested the robustness of the model.

In general, both environmental awareness and knowledge had significant positive effects on residents' willingness to participate in ecological restoration actions. This finding means that appropriately raising public awareness can effectively win public support for implementing RPER programs. The analytic results of the moderating effects showed that environmental knowledge weakened the positive impact of environmental awareness on residents' willingness to participate. As residents' environmental knowledge increases, their environmental awareness had a weaker positive effect on their willingness to participate in ecosystem- improvement actions. The DH model assessment results indicate that environmental knowledge and awareness have different effects on the two stages in residents' decision to participate in RPER. Environmental awareness affected only residents' wish to PN in stage 1 . In contrast, environmental knowledge affected residents' willingness to participate in both stages (their wish to PN and their DWP). This finding suggests that more advanced environmental knowledge encourages residents to participate in ecological restoration and raises their degree of participation.

Based on the results above, we recommend that policymakers should pay attention to the importance of environmental knowledge and awareness in ecological restoration programs. They should promptly inform the public about the implementation background, targets, operational mechanism, and expected effects of such programs so that residents can have sufficient access to information about such programs. The government should further optimize the means of promoting environmental protection. Protecting the ecological environment is a responsibility shared by society but promoting it should be tailored to different residential groups and the specific characteristics of regions. The government should strategically select the critical points of campaigns and their promotional materials to raise residents' environmental awareness and increase their knowledge about ecological restoration programs to improve public participation and effectively facilitate ecosystem program implementation.

Author Contributions: Conceptualization, T.X., N.X. and Y.G.; methodology, Y.G. and T.X.; software, Y.G.; validation, J.X. and D.Q.; formal analysis, Y.G.; investigation, T.X. and D.Q.; data curation, Y.G.; writing-original draft preparation, Y.G.; writing-review and editing, T.X., N.X. and D.Q.; visualization, Y.G.; supervision, T.X. and N.X.; funding acquisition, T.X. All authors have read and agreed to the published version of the manuscript. 
Funding: This research funded by Hainan Provincial Natural Science Foundation of China (719QN198), Natural Rubber Industry Operation Early-warning System Construction Project(18200125), Industrial Economic Position of China National Natural Rubber Industry Technical System (CARS-34-CJ1), National Natural Science Foundation of China (No. 72003054), China Engineering Science and Technology Development Strategy Hainan Research Institute 2019 Consultation Research Major Project Subtopic (19-HN-ZD-03-5).

Institutional Review Board Statement: Not applicable.

Informed Consent Statement: Not applicable.

Data Availability Statement: The data presented in this study are available on request from the corresponding author. The data are not publicly available due to personal privacy and non-open access of the research program.

Acknowledgments: The authors wish to thank the Industrial Economic Position of China National Natural Rubber Industry Technical System for supporting this work.

Conflicts of Interest: We declare that there are no conflicts of interest.

\section{References}

1. Food and Agriculture Organization (FAO), 2020. FAOSTAT. Available online: http://www.fao.org/faostat/zh/\#search/rubber (accessed on 14 February 2020).

2. Ahrends, A.; Hollingsworth, P.M.; Ziegler, A.D.; Fox, J.M.; Chen, H.; Su, Y.; Xu, J. Current trends of rubber plantation expansion may threaten biodiversity and livelihoods. Glob. Environ. Chang. 2015, 34, 48-58. [CrossRef]

3. Blagodatsky, S.; Xu, J.; Cadisch, G. Carbon balance of rubber (Hevea brasiliensis) plantations: A review of uncertainties at plot, landscape and production level. Agric. Ecosyst. Environ. 2016, 221, 8-19. [CrossRef]

4. Zhai, D.-L.; Cannon, C.H.; Slik, J.W.F.; Zhang, C.-P.; Dai, Z.-C. Rubber and pulp plantations represent a double threat to Hainan's natural tropical forests. J. Environ. Manag. 2012, 96, 64-73. [CrossRef] [PubMed]

5. Tan, Z.-H.; Zhang, Y.-P.; Song, Q.-H.; Liu, W.-J.; Deng, X.-B.; Tang, J.-W.; Deng, Y.; Zhou, W.-J.; Yang, L.-Y.; Yu, G.-R.; et al. Rubber plantations act as water pumps in tropical China. Geophys. Res. Lett. 2011, 38, 24. [CrossRef]

6. Luo, J.Y.; Liu, G.M. Thoughts on the Construction of Environment-friendly Rubber Plantation in Jinghong Farm. South China Agric. 2015, 9, 140-142.

7. Lan, G.Y.; Wu, Z.X.; Xie, G.S.; Huang, H.S. The theoretical basis of Environment-friendly Rubber Plantation. China Trop. Agric. 2014, 5, 64-73. [CrossRef]

8. Bureau of Agricultural Reclamation under the Ministry of Agriculture and Rural Affairs in 2020. Available online: http: / / www.moa.gov.cn/ztzl/2020gzzd/gsjgzyd/202002/t20200220_6337435.htm (accessed on 5 March 2020).

9. Yao, X.; He, J.; Bao, C. Public participation modes in China's environmental impact assessment process: An analytical framework based on participation extent and conflict level. Environ. Impact Assess. Rev. 2020, 84, 106400. [CrossRef]

10. Couix, N.; Gonzalo-Turpin, H. Towards a land management approach to ecological restoration to encourage stakeholder participation. Land Use Policy 2015, 46, 155-162. [CrossRef]

11. Min, S.; Bai, J.; Huang, J.; Waibel, H. Willingness of smallholder rubber farmers to participate in ecosystem protection: Effects of household wealth and environmental awareness. For. Policy Econ. 2018, 87, 70-84. [CrossRef]

12. Wang, Y.; Liang, J.; Yang, J.; Ma, X.; Li, X.; Wu, J.; Yang, G.; Ren, G.; Feng, Y. Analysis of the environmental behavior of farmers for non-point source pollution control and management: An integration of the theory of planned behavior and the protection motivation theory. J. Environ. Manag. 2019, 237, 15-23. [CrossRef] [PubMed]

13. Hou, C.; Zhou, L.; Wen, Y.; Chen, Y. Farmers' adaptability to the policy of ecological protection in China-A case study in Yanchi County, China. Soc. Sci. J. 2018, 55, 404-412. [CrossRef]

14. Ma, S.; Swinton, S.M.; Lupi, F.; Jolejole-Foreman, C. Farmers' willingness to participate in Payment-for-Environmental-Services programs. J. Agric. Econ. 2012, 63, 604-626. [CrossRef]

15. Lihua, W.U.; Tianshu, M.A.; Yuanchao, B.; Sijia, L.I.; Zhaoqiang, Y.I. Improvement of regional environmental quality: Government environmental governance and public participation. Sci. Total Environ. 2020, 717, 137265.

16. Tu, Z.; Hu, T.; Shen, R. Evaluating public participation impact on environmental protection and ecological efficiency in China: Evidence from PITI disclosure. China Econ. Rev. 2019, 55, 111-123. [CrossRef]

17. Xu, T.; Ni, Q.; Yao, L.; Qiao, D.; Zhao, M. Public Preference Analysis and Social Benefits Evaluation of River Basin Ecological Restoration: Application of the Choice Experiments for the Shiyang River, China. Discret. Dyn. Nat. Soc. 2020, 2020. [CrossRef]

18. Pan, X.; Xu, L.; Yang, Z.; Yu, B. Payments for ecosystem services in China: Policy, practice, and progress. J. Clean. Prod. 2017, 158, 200-208. [CrossRef]

19. Zhang, H.; Lei, S.L. A structural model of residents' intention to participate in ecotourism: The case of a wetland community. Tour. Manag. 2012, 33, 916-925. [CrossRef] 
20. Dwivedy, M.; Mittal, R.K. Willingness of residents to participate in e-waste recycling in India. Environ. Dev. 2013, 6, 48-68. [CrossRef]

21. Yang, R.; Long, R. Analysis of the influencing factors of the public willingness to participate in public bicycle projects and intervention strategies-A case study of Jiangsu Province, China. Sustainability 2016, 8, 349. [CrossRef]

22. Nnorom, I.C.; Ohakwe, J.; Osibanjo, O. Survey of willingness of residents to participate in electronic waste recycling in Nigeria-A case study of mobile phone recycling. J. Clean. Prod. 2009, 17, 1629-1637. [CrossRef]

23. Wang, Z.; Zhang, B.; Yin, J.; Zhang, X. Willingness and behavior towards e-waste recycling for residents in Beijing city, China. J. Clean. Prod. 2011, 19, 977-984. [CrossRef]

24. Sarvilinna, A.; Lehtoranta, V.; Hjerppe, T. Willingness to participate in the restoration of waters in an urban-rural setting: Local drivers and motivations behind environmental behavior. Environ. Sci. Policy 2018, 85, 11-18. [CrossRef]

25. Inglehart, R. Public support for environmental protection: Objective problems and subjective values in 43 societies. PS Political Sci. Politics 1995, 28, 57-72. [CrossRef]

26. Diekmann, A.; Franzen, A. The wealth of nations and environmental concern. Environ. Behav. 1999, 31, 540-549. [CrossRef]

27. Paço, A.; Lavrador, T. Environmental knowledge and attitudes and behaviors towards energy consumption. J. Environ. Manag. 2017, 197, 384-392. [CrossRef] [PubMed]

28. Melindi-Ghidi, P.; Dedeurwaerdere, T.; Fabbri, G. Using environmental knowledge brokers to promote deep green agrienvironment measures. Ecol. Econ. 2020, 176, 106722. [CrossRef]

29. Liu, P.; Teng, M.; Han, C. How does environmental knowledge translate into pro-environmental behaviors?: The mediating role of environmental attitudes and behavioral intentions. Sci. Total Environ. 2020, 728, 138126. [CrossRef]

30. Bassi, I.; Gori, E.; Iseppi, L. Assessing environmental awareness towards the protection of the Alps: A case study. Land Use Policy 2019, 87, 104028. [CrossRef]

31. Kikuchi-Uehara, E.; Nakatani, J.; Hirao, M. Analysis of factors influencing consumers' pro-environmental behavior based on life cycle thinking. Part I: Effect of environmental awareness and trust in environmental information on product choice. J. Clean. Prod. 2016, 117, 10-18. [CrossRef]

32. Zsóka, Á.; Szerényi, Z.M.; Széchy, A.; Kocsis, T. Greening due to environmental education? Environmental knowledge, attitudes, consumer behavior and everyday pro-environmental activities of Hungarian high school and university students. J. Clean. Prod. 2013, 48, 126-138. [CrossRef]

33. Zsóka, Á.N. Consistency and "awareness gaps" in the environmental behavior of Hungarian companies. J. Clean. Prod. 2008, 16, 322-329. [CrossRef]

34. Xu, X.; Wang, S.; Yu, Y. Consumer's intention to purchase green furniture: Do health consciousness and environmental awareness matter? Sci. Total Environ. 2020, 704, 135275. [CrossRef] [PubMed]

35. Gadenne, D.L.; Kennedy, J.; McKeiver, C. An empirical study of environmental awareness and practices in SMEs. J. Bus. Ethics 2009, 84, 45-63. [CrossRef]

36. Eiswerth, M.E.; Yen, S.T.; van Kooten, G.C. Factors determining awareness and knowledge of aquatic invasive species. Ecol. Econ. 2011, 70, 1672-1679. [CrossRef]

37. Kamaruddin, S.M.; Ahmad, P.; Alwee, N. Community awareness on environmental management through local agenda 21 (LA21). Procedia-Soc. Behav. Sci. 2016, 222, 729-737. [CrossRef]

38. Fu, L.; Sun, Z.; Zha, L.; Liu, F.; He, L.; Sun, X.; Jing, X. Environmental awareness and pro-environmental behavior within china's road freight transportation industry: Moderating role of perceived policy effectiveness. J. Clean. Prod. 2020, 252, 119796. [CrossRef]

39. Faccioli, M.; Czajkowski, M.; Glenk, K.; Martin-Ortega, J. Environmental attitudes and place identity as determinants of preferences for ecosystem services. Ecol. Econ. 2020, 174, 106600. [CrossRef]

40. Gkargkavouzi, A.; Halkos, G.; Matsiori, S. How do motives and knowledge relate to intention to perform environmental behavior? Assessing the mediating role of constraints. Ecol. Econ. 2019, 165, 106394. [CrossRef]

41. Pothitou, M.; Hanna, R.F.; Chalvatzis, K.J. Environmental knowledge, pro-environmental behavior and energy savings in households: An empirical study. Appl. Energy 2016, 184, 1217-1229. [CrossRef]

42. Gifford, R.; Nilsson, A. Personal and social factors that influence pro-environmental concern and behavior: A review. Int. J. Psychol. 2014, 49, 141-157.

43. Ogbeide, O.A.; Ford, C.; Stringer, R. The environmental benefits of organic wine: Exploring consumer willingness-to-pay premiums? J. Food Prod. Mark. 2015, 21, 482-502. [CrossRef]

44. Levine, D.S.; Strube, M.J. Environmental attitudes, knowledge, intentions and behaviors among college students. J. Soc. Psychol. 2012, 152, 308-326. [CrossRef] [PubMed]

45. Kaiser, F.G.; Roczen, N.; Bogner, F.X. Competence formation in environmental education: Advancing ecology-specific rather than general abilities. Umweltpsychologie 2008, 12, 56-70.

46. Kaiser, F.G.; Gutscher, H. The proposition of a general version of the theory of planned behavior: Predicting ecological behavior 1. J. Appl. Soc. Psychol. 2003, 33, 586-603. [CrossRef]

47. Maichum, K.; Parichatnon, S.; Peng, K.-C. Application of the extended theory of planned behavior model to investigate purchase intention of green products among Thai consumers. Sustainability 2016, 8, 1077. [CrossRef] 
48. Otto, S.; Pensini, P. Nature-based environmental education of children: Environmental knowledge and connectedness to nature, together, are related to ecological behavior. Glob. Environ. Chang. 2017, 47, 88-94. [CrossRef]

49. Kollmuss, A.; Agyeman, J. Mind the gap: Why do people act environmentally and what are the barriers to pro-environmental behavior? Environ. Educ. Res. 2002, 8, 239-260. [CrossRef]

50. Steg, L.; Vlek, C. Encouraging pro-environmental behavior: An integrative review and research agenda. J. Environ. Psychol. 2009, 29, 309-317. [CrossRef]

51. Adzawla, W.; Kudadze, S.; Mohammed, A.R.; Ibrahim, I.I. Climate perceptions, farmers' willingness-to-insure farms and resilience to climate change in Northern region, Ghana. Environ. Dev. 2019, 32, 100466. [CrossRef]

52. Rao, E.J.O.; Qaim, M. Supermarkets and agricultural labor demand in Kenya: A gendered perspective. Food Policy 2013, 38, 165-176. [CrossRef]

53. Ricker-Gilbert, J.; Jayne, T.S.; Chirwa, E. Subsidies and crowding out: A double-hurdle model of fertilizer demand in Malawi. Am. J. Agric. Econ. 2011, 93, 26-42. [CrossRef]

54. Xu, Z.; Burke, W.J.; Jayne, T.S.; Govereh, J. Do input subsidy programs "crowd in" or "crowd out" commercial market development? Modeling fertilizer demand in a two-channel marketing system. Agric. Econ. 2009, 40, 79-94. [CrossRef]

55. Wooldridge, J.M. Econometric Analysis of Cross Section and Panel Data; MIT Press: Cambridge, MA, USA, $2010 ;$ ISBN 0262296799.

56. McConnell, A.R.; Leibold, J.M. Weak criticisms and selective evidence: Reply to Blanton et al. (2009). J. Appl. Psychol. 2009, 94, 583-589. [CrossRef]

57. Hensher, D.A.; Rose, J.M.; Greene, W.H. Applied Choice Analysis: A Primer; Cambridge University Press: Cambridge, UK, 2005.

58. Sinacore, J.M. Multiple Regression: Testing and Interpreting Interactions; Leona, S.A., Stephen, G.W., Eds.; Sage: Newbury Park, CA, USA, 1991; p. 212.

59. Statistical Bureau of Hainan Province. Hainan Statistical Yearbook; China Statistical Publishing House: Beijing, China, 2019.

60. Xiao, H.F.; Tian, Y.H.; Zhou, H.P.; Ai, X.S.; Yang, X.D.; Schaefer, D.A. Intensive rubber cultivation degrades soil nematode communities in Xishuangbanna, southwest China. Soil Biol. Biochem. 2014, 76, 161-169. [CrossRef]

61. Sun, R.; Wu, Z.; Chen, B.; Yang, C.; Qi, D.; Lan, G.; Fraedrich, K. Effects of land-use change on eco-environmental quality in Hainan Island, China. Ecol. Indic. 2020, 109, 105777. [CrossRef]

62. Chen, B.; Li, X.; Xiao, X.; Zhao, B.; Dong, J.; Kou, W.; Qin, Y.; Yang, C.; Wu, Z.; Sun, R. Mapping tropical forests and deciduous rubber plantations in Hainan Island, China by integrating PALSAR 25-m and multi-temporal Landsat images. Int. J. Appl. Earth Obs. Geoinf. 2016, 50, 117-130. [CrossRef]

63. Zhou, C.; Li, G.P. A Review of Evaluation Methods of Ecosystem Services: Also on the Theoretical Progress of Contingent Valuation Method. Ecol. Econ. 2018, 34, 209-216.

64. Loomis, J.; Kent, P.; Strange, L.; Fausch, K.; Covich, A. Measuring the total economic value of restoring ecosystem services in an impaired river basin: Results from a contingent valuation survey. Ecol. Econ. 2000, 33, 103-117. [CrossRef]

65. Mahieu, P.-A.; Riera, P.; Giergiczny, M. Determinants of willingness-to-pay for water pollution abatement: A point and interval data payment card application. J. Environ. Manag. 2012, 108, 49-53. [CrossRef]

66. Chen, H.G.; Wang, Q.D.; Li, C.Y. WTP guidance technology: A comparison of payment card, single-bonded and double-bounded dichotomous formats for evaluating non-use values of Sanjiang Plain ecotourism water resources. Chin. J. Appl. Ecol. 2014, 25, 2709-2715.

67. Whittington, D. Improving the performance of contingent valuation studies in developing countries. Environ. Resour. Econ. 2002, 22, 323-367. [CrossRef]

68. Sardana, K. Tourists' Willingness to Pay for Restoration of Traditional Agro-forest Ecosystems Providing Biodiversity: Evidence from India. Ecol. Econ. 2019, 159, 362-372. [CrossRef]

69. Solomon, B.D.; Johnson, N.H. Valuing climate protection through willingness to pay for biomass ethanol. Ecol. Econ. 2009, 68, 2137-2144. [CrossRef]

70. Haryanto, B.; Budiman, S. The role of environmental knowledge in moderating the consumer behavioral processes toward the Green products (survey on the Green product-mind in Indonesian). Rev. Integr. Bus. Econ. Res. 2014, 4, $203-216$.

71. Lu, X.; White, H. Robustness checks and robustness tests in applied economics. J. Econom. 2014, 178, 194-206. [CrossRef] 